in the shortest possible period; but, unfortunately, the said promise was forgotten, for only one part made its appearance in November, 1844, and from that time until March, 1846, when another solitary part was issued to fill up the hiatus from November, 1844: April, 1847, a period of twentynine months, no tidings were heard of the work; and, to make bad worse, the articles on Ovary, Ovum, and Pancreas, are to be put into a Supplement; and part twenty-eight, which ought to have finished with article Morbid Products, as promised in part twenty-seven, March, 1846, terminates with the article Pisces, the article Pelvis being omitted in toto. The article Nervous Centres commenced in January, 1844 , and is continued in portions in parts twenty-five, twentysix, twenty-seven, and terminated in part twenty-eight, April, 1847. Nervous System, (Physiology of,) which ought to have appeared in November, 1844, is delayed to April, 1847, both articles being written by Dr. Todd. An advertisement in part twenty-eight, informs us we are to have the honour of another volume, which the editor hopes may be completed in six parts.

Mr. Editor, I have now given you a detailed account of the manner in which this work (a highly valuable one) has issued from the press, and I do hope you will take up your able pen to bring both the authors and the editor to their senses. I, in common, doubtless, with many others, commenced taking in the work for its intrinsic value; but how often have $I$ regretted the step I then took, when having occasion to refer to works of a similar description, and would gladly have availed myself of its contents for authorities, to have found that the article I most wanted was not yet out, and had to wait for an indefinite period before I could proceed with that which I had in hand. Independent of all these annoyances, the price of the work is so much enhanced, without a prospect of its being completed for years to come, if it progresses at its present rate. Pray is there no legal redress against either the editor or authors, or both ? I am also an unfortunate subscriber to Dr. Copland's "Dictionary," which is in a similar state of irregularity as the "Cyclopædia."-I have the honour to be, your obedient servant,

VERAX.

November, 1847 .

P.S.-I enclose my card.

\section{NEW PLAN OF POOR-LAW MEDICAL RELIEF.} To the Editor of THE LANCET.

SIR,-An interesting communication in ThE LANCET of the 13th, signed E. M. R., and headed, "New Plan of Poor-law Medical Relief," induces me to offer you a few remarks on the matters to which it relates.

The plan proposed for the Bangor and Beaumaris Union, as cited by your correspondent, presents some obvious advantages over established usage; the chief amendment consisting in the separate provision of all medicines and appliances by the local authorities, at a central dispensary, with branch depots in convenient localities, and the medical officers being engaged at suitable salaries, in lieu of all medical and surgical fees.

It is needless for me now to defend so manifest an improvement. The tide of public opinion has turned in its favour, and we may hope that the apathy, if not disinclination, of a portion of our profession towards such an alteration, will soon be succeeded by unanimous efforts to promote its general adoption. One of my objects in alluding to it, is to remind your readers that this feature of the Bangor plan is by no means a "new" one. The separate supply of medicines \&c. was repeatedly, and for many years, urged by the former poor-law committees of the Provincial Medical and Surgical Association. It was supported by several of the gentlemen who gave evidence before Lord Ashley's committee in 1844, and it was shown from statistical observations on a large scale, by two of the witnesses, Mr. Ceely and myself, to be generally practicable, and easy of application.

The other peculiarity of the Bangor propositions so much land $\mathrm{d}$ by your correspondent E. M. R.,-viz., the prohibition of the medical officers from private practice, has no greater claims than the former to be called "new." It has been tried in at least one other union, and has not been found to answer.

The intentions of the promoters of the plan, as E.M.R. states, have doubtless been, primarily, to secure the undivided attention of the medical officer to the objects of his official charge, and to create in his mind a permanent interest in his appointment; and secondarily, perhaps, to neutralize the objections of the established practitioners.

These intentions cannot be said to be fulfilled, when the medical officer holds his appointment only so long as may be requisite to obtain a reputation in the neighbourhood. Then the step to private practice is, naturally enough, kicked aside; the poor are turned over, en masse, to arother stranger; and the resident practitioners are unexpectedly favoured with a competitor, who commences private practice under the most advantageous auspices for a successful career. But this result, it will be said, may prove anything but an injury to society. I merely mention it, therefore, as a hint to those whom it may concern. Verbum sat.

More serious consequences, however, attend the separation of medical practice among the poor from that among other classes of the community. To raise a sufficient income for a medical officer, depending solely on public employment, the present unduly large districts must be still more widely extended. "It would be necessary," says E. M. R., "to enlarge or rather amalgamate several districts into one?"

A strange method this, indeed, of obviating the objections so reasonably entertained, and so often urged against the custom of "amalgamating" parishes into large medical districts, in utter forgetfulness of the helplessness of the poor, and their need of ready access to the source of medical aid!

One of the resolutions recently passed at the Poor-law Medical Convention briefly corroborates all that has been said respecting medical districts, thus:-

"That, in many instances, the number of persons amongst whom the casualties of disease and accident may occur, and the area to be traversed in visiting the patients, are so great, as to render early, constant, and satisfactory attendance, physically impossible."

I cannot pass on without referring to the conclusive evidence of my colleague, Mr. Ceely, on this point.

\section{Extracts from the Evidence of Mr. Ceely, $11 \mathrm{July}, 1844:-$}

"9405. ... I will assert, from extensive information, as well as from personal observation and experience, that the inevitable results of appointing one individual to districts of this extent, are injurious to the poor and the ratepayers. Delay and difficnlty arise to the sick in procuring medical aid; they are frequently and unjustly thrown on the gratuitous assistance of the nearest medical practitioner, and acute cases cannot obtain that amount of attention from the medical officer which they require."

" $9407 . .$. T think that the union of private with public practice is desirable; frrst, that it is more satisfactory to the poor; secondly, that it is beneficial to them to have the advantage of the long and varied experience of established practitioners; thirdly, that it is equally beneficial to the ratepayers also to have the advantage of medical experience gained from an attendance on the poor, more particularly during the prevalence of epidemics, which generally attack the poor early, and in large numbers; fourthly, it is unnecessary to resort to the mode pursued in the Leighton Buzzard Union, since respectable and established men are ready to do the duty on reasonable terms; fifthly, I would suggest that this mode is more expensive (particularly in rural districts) if the districts are of the proper size; and, sixthly, that it is impracticable in large rural districts; the duty cannot be properly performed by one person; an adequate number without private practice would be too expensive."

In the face of the almost unanimous testimony of philanthropic persons, both in and out of the profession, he must be a bold innovator, indeed, who would propose an increased extent of medical relief districts. May this chimerical proposition ascend, among forgotten things, into the limbo of vanities!

The third feature in E. M. R.'s plan,-viz., combining sanitary functions with the duties of the district medical attendant,-although newer than the other two, is not original, as any one may perceive who will take the trouble to read our evidence in 1844, and a pamphlet which I have since published on the subject.*

Let me invoke your powerful advocacy of this most important reform.

The establishment of an effective system of medical police will, I believe, be found incompatible with the present restricted system of poor-law medical relief. Indeed, the most superficial observer must be struck with the manifest inadequacy of existing arrangements to meet the awful visitation with which England is again threatened.

It has long appeared to me, that the great obstacle to sound legislation respecting the medical care of the poorer classes

* "The Health and Sickness of Town Populations," Parker, London. The second part of this pamphlet contains the only examination, as far as I know, hitherto given to the public, of the voluminous evidence taken by the Medical Relief Committee. 
has been the contracted and partial aspect in which this question has been viewed, both by our profession and by Parliament. It has been treated merely as a detail of poor-law. relief, and as such, the affair of poor-law commissioners, boards of guardians, and their officers.

My earnest endeavour, both before the parliamentary committee, in 1844, and in the little work before mentioned, has been, to show that attention to the diseases of the poor has a far wider bearing, and that it ought to be regulated by the sanitary code of laws which the legislature was then, and has ever since been, about to enact.

I would briefly submit my views on this subject in the form of a proposition, thus:-

The public safety requires, that in every district of limited extent, there should be a fully-qualified medical practitioner, employed by the State, not only to visit the sick paupers and to attend such casual applicants as may be in any way chargeable to the public, but also to investigate the saritary condition of all the poor within his district; to aid in bettering that condition by frequent inspection of their dwellings, and by timely counsel; to verify the fact, and record the cause, of every death; to examine or to be present at the examination of 'every corpse subjected to medico-legal investigation; to ascertain, at stated times, the proportion of the population suffering from disease; to carry into effect all those preventive regulations which are committed to medical men, as, for instance, vaccination; to report on the foregoing and other correlative matters to the constituted authorities; and, finally, to coöperate with the proposed inspectors or officers of health, (whose duties should be those of superintendence, advice, extended inquiry, and communication with the Government, ) in adopting measures for the prevention of sickness and mortality.

The success of the present movement of union medical officers, I believe, will entirely depend on their convincing the Government and legislature, that the office of district surgeon may be made one of vastly increased public utility, by the annexation of these sanitary functions-some of which bave already been committed, though under very imperfect supervision, to the union medical officers. Let the whole be connected in a comprehensive plan, and they will then array the intelligence and sympathy of the community in their support, instead of encountering at least the passive opposition of some influential classes.

If another order of district medical officers, (of Health,) as was proposed, both in Lord Morpeth's last Health of Towns Bill, and in Lord Lincoln's former measure, should be created, under local commissioners,-without reference to the existence of a large body of union surgeons,-there is reason to fear, that the meritorious labours of the latter will be still further depreciated, their position interfered with, and their functions unpleasantly limited and controlled.

The only sure method of preventing such a collision, and, at the same time, of emancipating the profession from the thraldom of boards of guardians, and the dictation of officials wholly uninformed on medical matters, would be, to place the district medical officers under the supervision of the proposed medical inspectors, who should be charged with circuits sufficiently extensive to free them from the shackles of local infuence, to relieve them from the restraints and liabilities of private practice, and to afford them enlarged opportunities of observing and comparing the important fact brought under their notice.

Let me, then, be permitted to advise union medical officers to seize the present favourable opportunity of securing their hold upon sanitary employment, and to consider the augmentation of their salaries as a secondary question.

The organization of such a sanitary corps as I now suggest, would necessarily involve a liberal remuneration for medical services; and the mode of calculating such remuneration would be simplified. Instead of reckoning so much for each case of sickness, (a very unsatisfactory arrangement for the sick poor, ) or limiting the payment of the medical officer to one portion of his duties, he would be fairly salaried for preventing the occurrence of these very cases, and would rise proportionately in public confidence and estimation.

To complete the beneficial change of system, the supply of medicines must be made a distinct affair, as already recommended; the articles required for the treatment of the sickwhether drugs, baths, or restorative appliances-being provided by the authorities at depôts conveniently situated, and common to as many of the smaller districts as might be found practicable, or, in the unavoidable defect of such a dispensary, being paid for, at a fixed rate, to the individual supplying them.
A medical police establishment, such as I have now sketched out, might be worth contending for; and there is ground for hope that the present Government would regard it favourably, if laid before them in a suitable ahd impressive manner.

In conclusion, I would request the attention of your readers to the five heads of the plan which Mr. Ceely and I submitted to the parliamentary committee in 1844 , and which embodies much that I have now offered for your and their consideration.

"Heads of the Plan submitted to the Select Committee of the House of Commons on Medical Poor Relief, in 1844, by the Representatives of the Provincial Medical and Surgical Association.

First. That the provision of medical aid for the out-door poor be separated from the administration of the poor-laws.

Second. That the administration of medical aid be combined with the regulation of the sanitary condition of the labouring population, and be committed to authorities central and local, to be constituted expressly for the management of this department.

Fourth. 'That an adequate remuneration, equitably adjusted, be paid to a sufficient number of medical officers, appointed to take care of the poor, in conveniently arranged districts.

Fifth. That medicines be supplied to the sick poor by the proposed authorities, at the public expense; and that in places where the separate provision of medicine may be impracticable, the medical officers be paid, at a fixed rate, for the supply of the same.

Sixth. That the poor, when sick or hurt, be provided freely and promptly with medical aid, no official check being interposed between them and the relief they need; and that the receipt of medical relief shall not constitute them paupers." I am, Sir, your obedient servant,

Gloucester, Nov. 1847 .

H. WYLDBORE RUMSEY.

\section{POOR-LAW MEDICAL REMUNERATION. To the Editor of ThE LANCET.}

Sir,-As medical officer of the Ferriby district of the Sculcoates Poor-law Union, I, on the 17th of August last, kindly aided by my friends, Messrs. Hill, Anderson, and Lee, removed, above the knee, the leg of Maria $M-$, a pauper patient resident in this village. By the end of the month, the wound was perfectly healed. The knee-joint showed, on dissection, most extensive ulceration of cartilage, with caries of the several opposing surfaces of the femur, tibia, and patella. A considerable portion of the outer condyle of the femur was loose in the cavity, which opened externally by several sinuses.

After her recovery, $I$ forwarded to the guardians-along with a certificate by Mr. Hill, sanctioning the operation-my charge, as allowed by the poor-law commissioners, and November 10th ult. received the following:-

"Dear Sir,-The board of guardians being of opinion, that in the case of Maria M- the certificate of Mr. Hill should have been sent before the operation was performed, I am desired to request your attendance, on Tuesday morning next, at the meeting, between ten and eleven o'clock, in order that the guardians may receive further explanation, before paying the account.-I am, dear Sir, yours truly,

"Wm. Chatham, Clerk."

The following is part of the colloquy that ensued, on my attending to the foregoing request:-

Chairman-Well, Mr. Jackson, we think you ought to have acquainted us, before you performed this operation. Answer.-I know of no law, Sir, requiring it of me.

Chairman.-Well, we think you ought to have acquainted us with it. Do not you think it would have been better to have done so.

Answer.-As a matter of courtesy, I might have done so but I am guided by the general laws issued by the commissioners.

(After some dogmatical remarks by Mr. Chairman, and a sapiernt guardian near him,-)

Chairman.-Well, then, we must have a by-law, requiring information on these extraordinary cases, or we shall have The Times newspaper publishing, that we sanction an amputation by a private practitioner, that the guardians may have the leg to lock at. We could have obtained her adnission into the infirmary, and it would have cost us nothing.

After some further remarks, the chairman stated, that the 